\title{
Breeding of an Indigo Phalaenopsis by Intergeneric Hybridization: Rhynchonopsis Tariflor Blue Kid '1030-4'
}

\author{
Jung-Yi Wu \\ Floriculture Research Center, Taiwan Agriculture Research Institute, Council \\ of Agriculture, Yun Lin, Taiwan
}

\section{Ting-Fang Hsieh}

Plant Pathology Division, Taiwan Agricultural Research Institute, Council of Agriculture, Taichung City, Taiwan

Chin-Yi Tsao

Biotechnology Division, Taiwan Agricultural Research Institute, Council of Agriculture, Taichung City, Taiwan

\section{Keng-Chang Chuang \\ Floriculture Research Center, Taiwan Agriculture Research Institute, Council of Agriculture, Yun Lin, Taiwan}

Additional index words. orchid, hybrid, blue phalaenopsis, breed

Breeding for new phalaenopsis varieties has been conducted for many decades. With the efforts of breeders, a lot of varieties have been bred and sold in the market, including many colorful varieties with various flower sizes. However, new varieties are constantly being bred and selected every year and are expected to create new colors or new types that are different from those on the market. Breeding for indigo flowers has been a common goal for many breeders in the world. Currently, indigo Phalaenopsis is rarely seen on the commercial market. Most of them are crossed or backcrossed from certain species or commercial varieties such as Phal. equestris, Phal. pulcherrima, Phal. violacea, Phal. Kenneth Schubert, and Phal. Purple Martin, and only a few native blue species have been applied to blue Phalaenopsis hybridization (Tsao et al., 2020). Blue flowers of most plants are the result of delphinidin accumulation or expression (Qingyu and Silan, 2004), and in only a few cases (such as Phalaenopsis) is the blue color a result of cyaniding in flowers (Tatsuzawa et al., 2004). Blue flowers of most Phalaenopsis varieties faded easily without delphinidin expression as a result of the lack of the flavonoid 3',5'-hydroxylase gene. It is necessary to introduce other genes to the

Received for publication 28 Oct. 2021. Accepted for publication 1 Dec. 2021.

Published online 11 February 2022.

This research was supported in part by a grant from the Council of Agriculture, Executive Yuan, Taipei, Taiwan.

K.-C.C. is the corresponding author. E-mail: keng4891@gmail.com.

This is an open access article distributed under the CC BY-NC-ND license (https://creativecommons. org/licenses/by-nc-nd/4.0/).
Phalaenopsis genus by crossing with other genera or by transferring a gene or genes from other genera to create unique flower colors or characteristics. In our study, we introduced a stable blue color to Phalaenopsis from the genus Rhynchostylis to breed Rhynchonopsis Tariflor Blue Kid '1030-4' successfully with a deep and nonfading blue color.

\section{Origin}

Rhynchonopsis Tariflor Blue Kid '1030-4'. All the breeding, including crossing, selection, and performance studies, was carried out under natural greenhouse conditions at the Floriculture Research Center. Flowering plants of Phal. Fire Cracker and Rhynchostylis coelestis were grown in a pad and fan greenhouse. Phal. Fire Cracker was used as the seed parent that was crossed with Rhy. coelestis in Aug. 2007. Mature capsules were surface-sterilized with $70 \%$ ethanol, followed by $1.0 \%$ sodium hypochlorite solution for 20 min and rinsed three times with sterile distilled water. Capsules were cut open and the seeds were scooped out with forceps onto Murashige and Skoog medium that had halfstrength macroelements and full-strength microelements (Murashige and Skoog, 1962) supplemented with $100 \mathrm{mg} \cdot \mathrm{L}^{-1}$ myo-inositol, $0.5 \mathrm{mg} \cdot \mathrm{L}^{-1}$ niacin, $0.5 \mathrm{mg} \cdot \mathrm{L}^{-1}$ pyridoxine hydrogen chloride, $0.1 \mathrm{mg} \cdot \mathrm{L}^{-1}$ thiamine hydrogen chloride, $2.0 \mathrm{mg} \cdot \mathrm{L}^{-1}$ glycine, 20,000 $\mathrm{mg} \cdot \mathrm{L}^{-1}$ sucrose, $7000 \mathrm{mg} \cdot \mathrm{L}^{-1}$ Difco Bacto agar, and $1000 \mathrm{mg} \cdot \mathrm{L}^{-1}$ activated charcoal. The $\mathrm{pH}$ of the medium was adjusted to 5.7 before autoclaving at $121^{\circ} \mathrm{C}, 1.05 \mathrm{~kg} \cdot \mathrm{cm}^{-2}$ for $20 \mathrm{~min}$. The seeds were incubated at $25 \pm$ $1{ }^{\circ} \mathrm{C}$ under a 14-h photoperiod at an irradiance of $40 \mu \mathrm{mol} \cdot \mathrm{m}^{-2} \cdot \mathrm{s}^{-1}$ (daylight cool-white fluorescent light). Two hundred ninety-seven seedlings from flasks were grown in sphagnum moss under natural greenhouse conditions (20 to $30^{\circ} \mathrm{C}, 12-13.5-\mathrm{h}$ daylength). Irrigation was performed once every 1 to 2 weeks during the cultivation period. Peters $20 \mathrm{~N}-20 \mathrm{P}_{2} \mathrm{O}_{5}-20 \mathrm{~K}_{2} \mathrm{O}$ at $1.0 \mathrm{~g} \cdot \mathrm{L}^{-1}$ (Scotts Company, Marysville, $\mathrm{OH}$ ) was added to tap water as the fertilizer solution. Seedling plants flowered in July 2010, and this hybrid was registered as Rhnps. Tariflor Blue Kid. The cultivar '1030-4' was selected from more than 100 seedlings because of its darker blue flowers in July 2010. After that, the stalk was used to be propagated by tissue culture.

\section{Description and Performance}

Rhnps. Tariflor Blue Kid '1030-4' was bred and selected by crossing Phal. Fire Cracker with Rhy. coelestis. The characteristics of new cultivar are similar to those of Phalaenopsis. Phal. Freed's Beautiful Girl was used as the control variety and is compared to the new line. Rhnps. Tariflor Blue Kid '1030-4' had 24 traits that distinguish it from Phal. Freed's Beautiful Girl (Table 1) based on the distinctness, uniformity, and stability (DUS) test guideline for Phalaenopsis (International Union for the Protection of New Varieties of Plants, 2013). DUS testing is a way of judging whether a new variety differs from existing varieties within the same species (the distinctness part), whether the characteristics used to establish distinctness are expressed uniformly (the uniformity part), and whether these characteristics change (or not) through subsequent generations (the stability part) (An et al., 2014). The following color description was based on The Royal Horticultural Society's (RHS) color chart (Royal Horticultural Society, 2015). Plants of Rhnps. Tariflor Blue Kid '1030-4' are of medium size, with oval leaves, spots on the upper side of leaves, and darker green leaves. Plants of Phal. Freed's Beautiful Girl are large, with oval leaves, no spots on the upper side of leaves, and lighter green leaves. Rhnps. Tariflor Blue Kid '1030-4' has a greater average flower count $(n=15)$ than that of Phal. Freed's Beautiful Girl $(\mathrm{n}=8)$. The flower diameter of Rhnps. Tariflor Blue Kid '1030-4' and Phal. Freed's Beautiful Girl is $3.5 \mathrm{~cm}$ and $5 \mathrm{~cm}$, respectively (Fig. 1). The dorsal sepal of Rhnps. Tariflor Blue Kid '1030-4' and Phal. Freed's Beautiful Girl is moderately compressed and moderately elongated, respectively. The cross section of the dorsal sepal for Rhnps. Tariflor Blue Kid '1030-4' is concave, and the ground color of the upper side is moderate violet (RHS 86A). The cross section of the dorsal sepal for Phal. Freed's Beautiful Girl is straight, and the ground color of the upper side is strong purple (RHS N82A). The ground color of the upper side for the lateral sepal of Rhnps. Tariflor Blue Kid '1030-4' and Phal. Freed's Beautiful Girl is strong purple (RHS N87A) and strong purple (RHS N82A), respectively. The cross section of the petal for Rhnps. Tariflor Blue Kid ' 10304 ' is concave, and the ground color of the upper side is strong purple (RHS 
Table 1. Comparisons of Rhnps. Tariflor Blue Kid '1030-4' and Phal. Freed's Beautiful Girl plant, leaf, and flower based on the distinctness, uniformity, and stability (DUS) test guideline of Phalaenopsis.

Trait

Plant length (cm)

Leaf spots on upper side

Leaf color of upper side

Inflorescence, no. of flowers

Flower width in front view

Dorsal sepal shape

Dorsal sepal shape in cross section

Dorsal sepal ground color of upper side

Lateral sepal ground color of upper side

Lateral sepal overcolor (if present)

Petal shape of cross section

Petal ground color of upper side

Petal overcolor (if present)

Lip, size of lateral lobe relative to apical lobe

Apical lobe ground color

Apical lobe tip color

Apical lobe overcolor

Apical lobe tip overcolor

Apical lobe color of spots

Lateral lobe ground color

Lateral lobe overcolor

Callus color

Callus shape of pattern

Column apex color
Rhyn. Tariflor Blue Kid '1030-4'

Result

Medium: $25 \leq \times<40$

Present

Medium green

Medium

Very narrow

Moderately compressed

Concave

Moderate violet (RHS 86A)

Strong purple (RHS N87A)

Strong purple (RHS N87B)

Concave

Strong purple (RHS N82B)

Light purple (RHS N82D)

Equal

Very pale violet (RHS 91D)

Moderate violet (RHS 86A)

Very pale violet (RHS 91D)

Strong violet (RHS 86B)

Moderate violet (RHS 86A)

Strong violet (RHS 86B)

Strong violet (RHS 86C)

Very pale violet (RHS 91D)

Spots

Strong purple (RHS N82A)
Phal. Freed's Beautiful Girl

Long: $40 \leq \times \leq 65$

Absent

Light green

Few

Narrow

Moderately elongated

Straight

Strong purple (RHS N82A)

Strong purple (RHS N82A)

Light purple (RHS N82C)

Straight

Strong purple (RHS N87A)

Strong purple (RHS N87B)

Larger

Very pale purple (RHS 85D)

Strong purple (RHS N87A)

Very light purple (RHS 85C)

Strong purple (RHS N87B)

Deep purple (RHS 83B)

Strong purple (RHS N87B)

Brilliant purple (RHS N87C)

Brilliant yellow (RHS 12B)

None

Strong purple (RHS N87B)

RHS = Royal Horticultural Society.
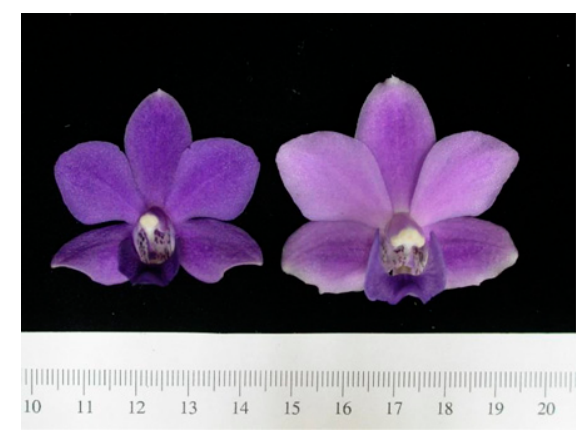

Fig. 1. Flower of Rhnps. Tariflor Blue Kid '1030-4' (left) and Phal. Freed's Beautiful Girl (right).

N82B). The cross section of the petal for Phal. Freed's Beautiful Girl is straight, and the ground color of the upper side is strong purple (RHS N87A). The size of the lateral lobe relative to the apical lobe for Rhnps. Tariflor Blue Kid '1030-4' is equal and large for Phal. Freed's Beautiful Girl, respectively. Lip traits of Rhnps. Tariflor Blue Kid '10304' are as follows: ground color, tip color, and spot color of the lip apical lobe are very pale violet (RHS 91D), moderate violet (RHS 86A), and moderate violet (RHS 86A) respectively. Lip traits of Phal. Freed's Beautiful Girl are as follows: ground color, tip color, and spot color of the lip apical lobe are very pale purple (RHS $85 \mathrm{D})$, strong purple (RHS 87A), and deep purple(RHS 83B), respectively. The callus color of Rhnps. Tariflor Blue Kid '1030-4' is very pale violet (RHS 91D) with spots, whereas the callus color of Phal. Freed's Beautiful Girl is brilliant yellow (RHS 12B) without spots. The apex color of the column of Rhnps. Tariflor Blue Kid '1030-4' and Phal. Freed's Beautiful Girl is strong purple (RHS N82A) and strong purple (RHS N87B), respectively.

\section{Availability}

Questions concerning Rhynchonopsis Tariflor Blue Kid '1030-4' and the research should be addressed to Dr. Jung-Yi Wu (E-mail: iris12@tari.gov.tw) at the Floriculture Research Center, Taiwan Agriculture Research Institute, Council of Agriculture, Taiwan.

\section{Literature Cited}

An, C.H., M.C. Liu, Z.H. Liu, and L.T. Kuo. 2014. Amendment of test guidelines for the new cultivars of Phalaenopsis. Seed Nursery (Taiwan) 16:49-69.

International Union for the Protection of New Varieties of Plants. 2013. TG/213/2 test guidelines of Phalaenopsis. International Union for the Protection of New Varieties of Plants, Geneva, Switzerland.

Murashige, T. and F. Skoog. 1962. A revised medium for rapid growth and bioassays with tobacco tissue culture. Physiol. Plant. 15:473-497, https:// doi.org/10.1111/j.1399-3054.1962.tb08052.x.

Qingyu, X. and D. Silan. 2004. Blue flowers' molecular breeding. Mol. Plant Breed. 2(1):93-99.

Royal Horticultural Society. 2015. The Royal Horticultural Society's color chart. 5th ed. Royal Horticultural Society, London, UK.

Tatsuzawa, F., N. Saito, H. Seki, M. Yokoi, T. Yukawa, K. Shinoda, and T. Honda. 2004. Acylated anthocyanins in the flowers of Vanda (Orchidaceae). Biochem. Syst. Ecol. 32:651664, https://doi.org/10.1016/j.bse.2004.02.004.

Tsao, C.Y., U.C. Chen, R.Y. Wu, T.Y. Wu, and C.N. Hsia. 2020. Polyploidization and selection of parents for improving breeding of blue-purple Phalaenopsis. J. Taiwan Agr. Res. 69:154-168, https://doi.org/10.6156/JTAR.202006_69(2).0005. 